\title{
Laparoscopic combined transperitoneal pelvic exenteration for vulvovaginal recurrence of rectal carcinoma following a Miles operation
}

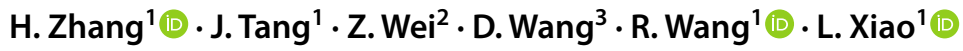

Received: 16 October 2021 / Accepted: 30 November 2021 / Published online: 1 January 2022

(c) The Author(s) 2021

Keywords Pelvic exenteration $\cdot$ Recurrent rectal carcinoma $\cdot$ Pelvic mass

Pelvic exenteration refers to a multivisceral resection of all pelvic organs, including the rectum, bladder, and reproductive organs [1]. Approximately $70 \%$ of appropriately selected patients can receive $\mathrm{R} 0$ resection [2] with a potential of improved quality of life, prolonged survival, and even clinical cure. The attached video shows laparoscopic combined transperitoneal pelvic exenteration for vulvovaginal recurrence of rectal carcinoma following a Miles operation.

The patient is a 37-year-old woman who 5 years previously had undergone a Miles operation for pT1N0M0 stage I rectal adenocarcinoma and, 2 years later was diagnosed with a subcapsular tumor in segment VI of the liver and a pelvic mass involving the right pelvic wall. After three surgeries for metastatic tumors, a hemorrhagic neoplasm in the vulvovaginal region was found on physical examination. Biopsy confirmed locally recurrent rectal adenocarcinoma. The right ureter was involved and a mild hydronephrosis was present. Therefore, we performed a laparoscopic combined transperitoneal pelvic exenteration and bilateral cutaneous ureterostomy in March 2021. The pelvic floor defect was repaired with a biological graft and adjacent soft tissue.

Operation time was $480 \mathrm{~min}$. Blood loss was $600 \mathrm{ml}$. Complete tumor clearance was achieved without any

\section{Xiao}

xiaolin@hospital.cqmu.edu.cn

1 Department of Gynecology, The First Affiliated Hospital of Chongqing Medical University, Chongqing 400016, China

2 Department of Gastrointestinal Surgery, The First Affiliated Hospital of Chongqing Medical University, Chongqing, China

3 Department of Urological Surgery, The First Affiliated Hospital of Chongqing Medical University, Chongqing, China complications. After multidisciplinary team discussion, adjuvant radiotherapy was suggested as complementary treatment considering the lesion was close to the pubic symphysis and pelvic sidewall. Two months after the surgery, a follow-up computed tomography scan revealed no sign of recurrence or residual lesion. The patient's quality of life has greatly improved.

Laparoscopic combined transperitoneal pelvic exenteration is technically feasible for a laterally recurrent pelvic tumor and urethral-vaginal fistula after Miles operation and concurrent chemoradiotherapy.

Supplementary Information The online version contains supplementary material available at https://doi.org/10.1007/s10151-021-02562-0.

\section{Declarations}

Conflict of interest Hao Zhang, Junying Tang, Zhengqiang Wei, Delin Wang, Rong Wang, and Lin Xiao have no conflicts of interest or financial ties to disclose.

Ethical approval This paper was approved by the Ethics Committee of the institutional review board (IRB) of Chongqing Medical University.

Informed Consent A signed informed consent has been obtained from the patient.

Open Access This article is licensed under a Creative Commons Attribution 4.0 International License, which permits use, sharing, adaptation, distribution and reproduction in any medium or format, as long as you give appropriate credit to the original author(s) and the source, provide a link to the Creative Commons licence, and indicate if changes were made. The images or other third party material in this article are included in the article's Creative Commons licence, unless indicated otherwise in a credit line to the material. If material is not included in the article's Creative Commons licence and your intended use is not permitted by statutory regulation or exceeds the permitted use, you will need to obtain permission directly from the copyright holder. To view a copy of this licence, visit http://creativecommons.org/licenses/by/4.0/. 


\section{References}

Publisher's Note Springer Nature remains neutral with regard to jurisdictional claims in published maps and institutional affiliations.

1. Pawlik TM, Skibber JM, Rodriguez-Bigas MA (2006) Pelvic exenteration for advanced pelvic malignancies. Ann Surg Oncol $13: 612-623$

2. PelvExCollaborative (2019) Pelvic exenteration for advanced nonrectal pelvic malignancy. Ann Surg 270:899-905 